\title{
Investigating and Ranking Barriers to Strategic Implementation in Telecommunication Center of Tehran Province
}

\author{
Shirin Javaheri ${ }^{a^{*}}$, Ahmad Abdolvand ${ }^{\mathrm{b}}$, Aghdam Mohammadloo ${ }^{\mathrm{c}}$ \\ ${ }^{a}$ Young Researchers and Elite club, West Tehran Branch, Islamic Azad University, Tehran, Iran \\ ${ }^{b}$ MA of Management, Central Tehran Branch, Islamic Azad University, Tehran, Iran \\ ${ }^{c}$ Phd of Manangement, Qazvin Branch, Islamic Azad University, Qazvin, Iran
}

\begin{abstract}
This study sought to investigate and rank the barriers to strategic implementation in Telecommunication Center in Tehran province. In terms of the objectives, it is an applied study and with regard to the methodology, it is descriptive as it describes the conditions of phenomena. The statistical population consisted of 140 managers, senior experts and elites of Telecommunication Center of Tehran province. Using Morgan's table, a total of 90 people were selected as the study sample. The instrument to collect the required data was a researcher-made questionnaire. The validity of the questionnaire was confirmed by the experts in the field and the reliability within the pilot study was 0.87 . In this research, four barriers were raised including: system and management barriers, barriers related to employees, barriers to strategic planning, and barriers to non-allocation of resources.

Investigating the capability of fitting the strategic barriers model in Telecommunication Center of Tehran province revealed that all the barriers were within the acceptable limits. In this study, content validity was assessed using expert judgment and construct validity using the confirmatory factor analysis. The TOPSIS technique was then run to prioritize the barriers. Findings indicate that whereas the system and management barriers have the highest rank, the barriers related to employees have the lowest rank.
\end{abstract}

\section{Keywords:}

System and Management Barriers; Barriers Related to Employees;

Strategic Planning Barriers; Barriers to Resource Non-allocation; Telecommunications in Tehran Province.

\section{Article History:}

Received: 18 September 2017 Accepted: 05 January 2018

\section{1- Introduction}

For a long time since the strategic management discussion has been raised in organizations, the managers of a bulk of organizations have found solutions to their problems by investing in this category, and have come to believe that the growth and advancement of organizations' survival in turbulent conditions in the external environment of the organization to reduce costs and develop incomes is both the development of strategies and the implementation of those strategies [1].

Jokes and Gluck (1988) describe the implementation of strategy as a process that includes a consistent set of choices and actions for allocating resources, organizing, assigning key managers, regulating policies, procedures, policies, and the establishment of an executive system for strengthening, controlling and evaluating a strategy. The importance of implementing today's strategy has raised the issue of non-implementation of it as the most important challenge for managers [2]. Now, if the barriers to why strategies are more likely to fail in the implementation phase are recognized, we will see the success of executives in achieving strategic goals. In fact, the investigation of strategy barriers is like gears that help the strategy implementation as well as strategy plan move well (Figure 1).

\footnotetext{
*CONTACT: S_javaheri@ymail.com

DOI: http://dx.doi.org/10.28991/esj-2018-01124

(C) This is an open access article under the CC-BY license (https://creativecommons.org/licenses/by/4.0/).
} 


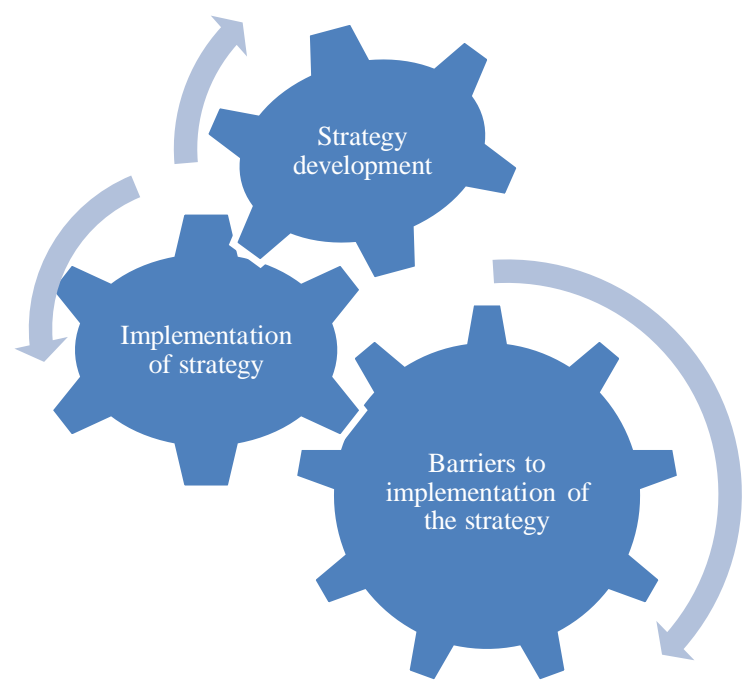

Figure 1. The relationship between strategic implementation and strategy barriers.

Research shows that there is a dearth of research on the investigation of the barriers of strategic failure in Iranian organizations suggesting that given the high costs and the use of strategic planning tools and methods, we have not been able to achieve competitive advantage. Special attention to identifying the factors affecting strategic failure or success help to prevent the unfortunate consequences of the implementation of such decisions.

Accordingly, the present study seeks to investigate the strategic barriers in Tehran Telecommunications in order to get rid of the current adverse conditions in the implementation of strategies and strategic plans. Identifying these barriers can help the organization in terms of income, quality, performance, etc., as well as in accomplishing its mission and in the further achievement of success. In other words, the research question in this study is what are the barriers to the implementation of Strategic planning in Tehran Telecommunications? And what is the ranking of available barriers? In this study, we strive to address the barriers to the implementation of the strategy as a whole, and these barriers are ranked using the Likert scale and TOPSIS decision making technique.

Accordingly, in the present study, designing and developing a model of barriers to the implementation of strategic plans in Telecommunications of Tehran province was studied and 19 factors in four fields were extracted through survey research.

\section{2- Literature Review}

It should be noted that there are a bulk of texts and studies on strategy development, but less attention has been paid to its implementation. The implementation of strategies has been the most complicated and time-consuming phase of the strategy and the most important issue in the defeat of the strategies in recent years. Some of the research in this line include:

Chukwumah and Ezeugbor (2015) reviewed "problems of implementation of strategic plans for secondary schools improvement in Anambra State", and identified the factors using exploratory factor analysis, which included pure theorizing, pure practice, purely administrative or hierarchical attitude, cultural infrastructure, financial constraints [3].

Trapp et al. (2017) conducted a research paper entitled Implementation and diffusion of innovative water infrastructures: obstacles, stakeholder networks and strategic opportunities for utilities [4]. This applied research was conducted in Germany. After studying the weaknesses and strengths, using swat matrix, strategic plans in the organization was identified [5].

Elbano (2016) conducted a study entitled " An Analysis of the Comprehensive Implementation of Strategic Plans in Emerging Economies: The United Arab Emirates as a Case Study." In order to study this research, they first reviewed the literature of the economies of developing countries', including Malaysia, Turkey and Thailand. Using statistical analysis and applying Factor Analysis, they extracted the main strategies including 22 ones among from 55 primary factors. Then, they used Friedman test to rank the factors [6].

Regarding the identification of strategic barriers, it can be used to assist the organization in terms of revenue, quality and performance, and to achieve strategic goals and to eliminate bottlenecks.

\section{3- Conceptual Model}

Review of the related literature raised the conceptual model of research in four forms according to Figure 2. 


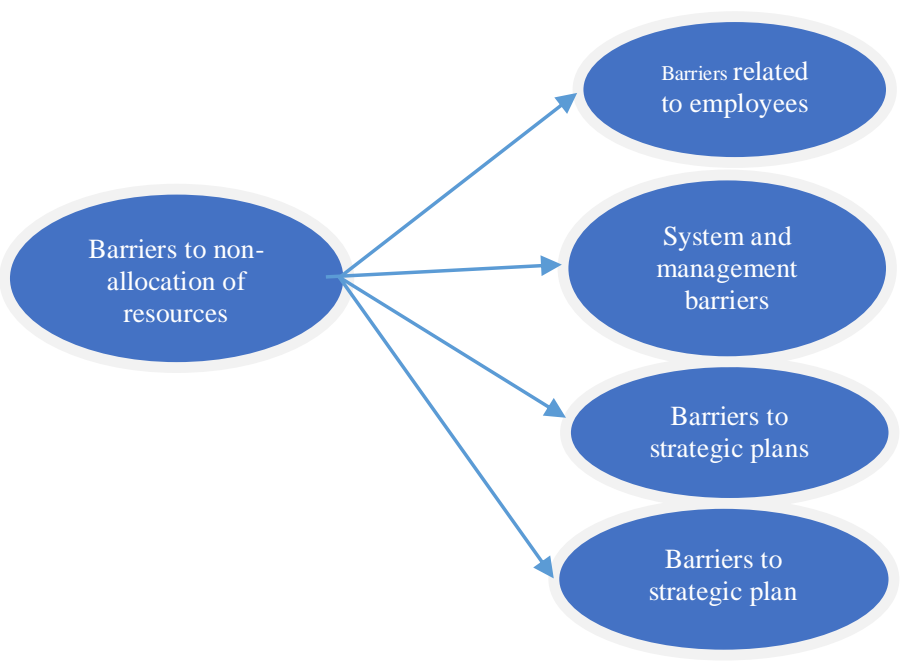

Figure 2. Research model.

\section{4- Definition of Strategic Barriers in the Conceptual Model of Research}

\section{4-1- System and Management Barriers}

Here, executives with the necessary vigilance strive to provide the required support in implementing the strategy. Leading senior executives, by holding strategy review sessions, show their commitment to strategy implementation. Also, with the implementation of the strategy, all the organizational processes and operating levels create the necessary framework in this regard. The existence of any barriers in this regard has a significant impact on the failure to implement the strategy.

\section{4-2- Barriers Related to Non-allocation of Resources}

Activities in the realm of Strategies and activities in the realm of resource allocation should not be separate from each other. In many cases, the separation of these will make a lot of rework. By connecting the budgeting process to the process of planning the strategy, it can be ensured that the strategies of the organization are implemented. The point that matters here is to pay attention to prioritizing these plans and to select programs that have the greatest impact on implementing the organization's strategy and spending the least resources.

\section{4-3- Barriers Related to Employees}

By passing the strategy to all levels of the organization, employees can demonstrate how their daily activities help to realize the company's strategy. If the organization's staff does not properly understand the organization's strategy, how can one expect them to help implement the strategy? Therefore, it is very important to use the appropriate mechanisms to transfer and communicate the strategy. All employees must consider their material interests and their work destined to realize the organization's strategies. If the implementation of the strategy brings about fame and financial achievement only for the management of the organization and that the other levels of management and the rest of the staff do not benefit, it certainly will not be enough incentive to support the strategy. Design and implementation of compensation systems linked to the strategy assessment criteria can provide an appropriate mechanism for more employee alignment with the strategy.

\section{4-4- Barriers to Strategic Planning}

Here the vision should be interpreted. As shown in Figure 3, the effect of the alignment of vision in operational levels is to measure the impact on quantitative targets, plans, initiatives, and indicators. 
Definition of Indicators and Initiatives

Definition of quantitative goals

Definition of strategic concepts

Definition of issues and bottlenecks and strategic goals

Definition of the vision

Figure 3. The alignment of the vision and its impact on indicators and initiatives

\section{5- Research Method}

The method of this research was to rank the strategic barriers in Telecommunications of Tehran province. In terms of the objectives, this study is an applied research. The method is descriptive because it describes the conditions with phenomena. In order to carry out the research, firstly, the barriers to strategic implementation were investigated and then Kolmogorov-Smirnov test was used to analyze the data. Then, a researcher-made questionnaire were distributed. The statistical population of this study consisted of 140 managers of Telecommunications in Tehran province. According to Morgan's table, 90 people were selected as samples. Doing a survey study, 19 factors in four areas were extracted. A researcher-made questionnaire was then given out among the experts. According to the reliability of the final questionnaire, the Cronbach's alpha coefficient was calculated which was 0.86 and represented a good level of reliability. The validity of the questionnaire was measured by experts and a confirmatory factor analysis running LISREL software. The Kolmogorov test was run to test the normal distribution of the data and a single-sample $\mathrm{T}$ test was run to identify the factors that contribute to strategy implementation. Confirmatory factor analysis was performed to model and verify the significant relationship between variables and finalize the research model. Moreover, TOPSIS was run to prioritize the variables. It is worth noting that the preliminary questionnaire included multiple choice questions. Table 1 illustrates the categories of barriers and the number of corresponding questionnaires. According to this table, this questionnaire contains 19 multiple choice questionnaires. The number of corresponding questions in each class is not necessarily the same and varies between 4 and 5.

Table 1. The titles of the classes and the number of corresponding questions in the final questionnaire

\begin{tabular}{cccc}
\hline Row & Kinds of barriers & $\begin{array}{c}\text { Number } \\
\text { of items }\end{array}$ & $\begin{array}{c}\text { Number of items in the } \\
\text { questionnaire }\end{array}$ \\
\hline 1 & System and management barrier & 5 & $1-5$ \\
\hline 2 & Barriers related to non-allocation of resources & 5 & $6-10$ \\
\hline 3 & Barriers related to employees & 5 & $11-15$ \\
\hline 4 & Barriers to strategic planning & 4 & $16-19$ \\
\hline Total & 4 barriers & $\mathbf{1 9}$ & $\mathbf{1 - 1 9}$ \\
\hline
\end{tabular}

The response alternatives for all the participants were the same and in accordance with a 5-point Likert scale as shown in Table 2. According to this Table, options 1 to 5 are quantitatively allocated.

Table 2. Response alternatives and encoding options.

\begin{tabular}{ccc}
\hline Row & Answer option & Numbers \\
\hline 1 & Too little & 1 \\
\hline 2 & Little & 2 \\
\hline 3 & Moderate & 3 \\
\hline 4 & Much & 4 \\
\hline 5 & Very much & 5 \\
\hline Mean answer option & $\mathbf{3}$ \\
\hline
\end{tabular}




\section{6- Confirmatory Factor Analysis}

The results of the confirmatory factor analysis in the form of the standard estimation model are shown in Figure 4. As is clear in this Figure, all the factor loads of the components and factors at a reasonable level.

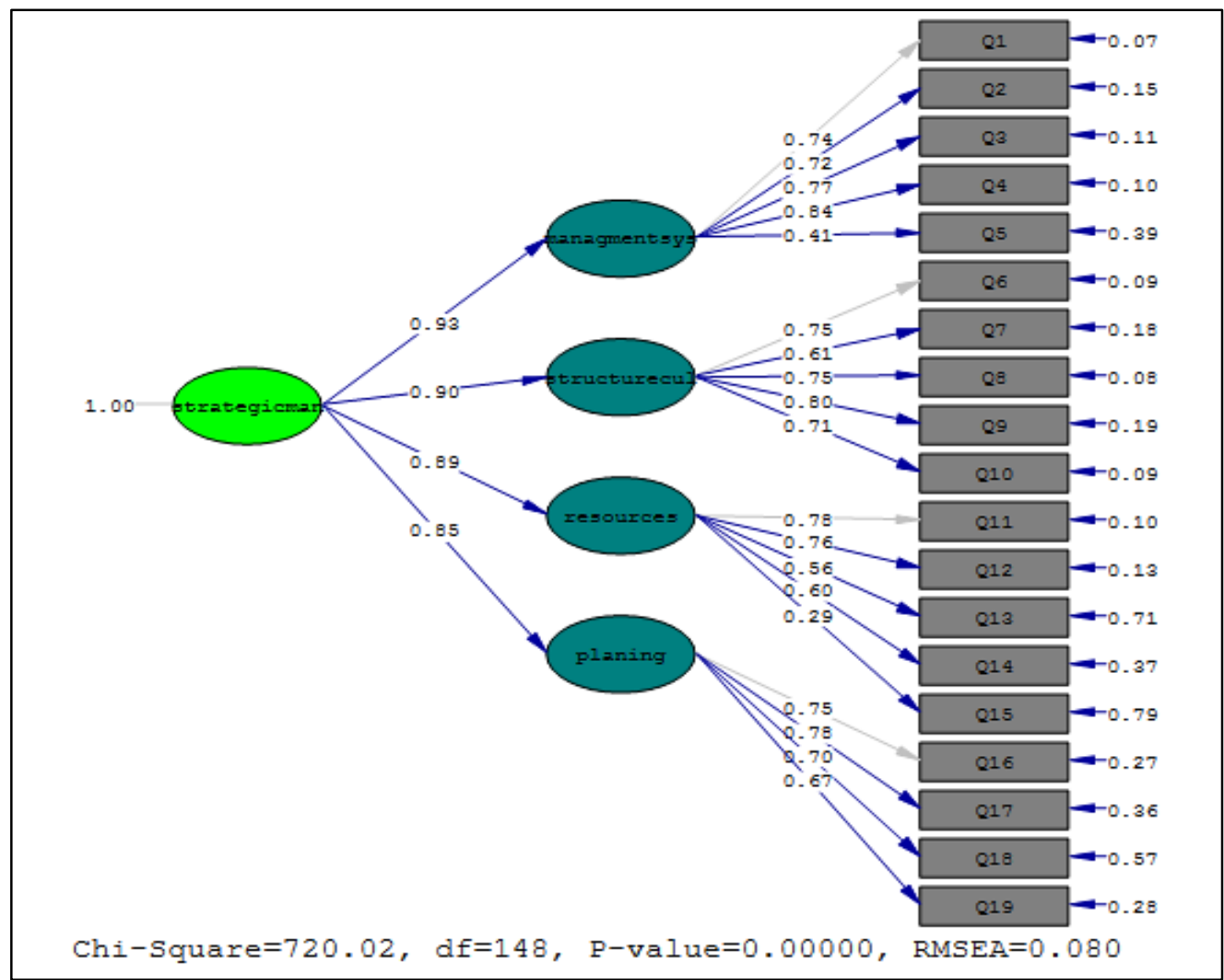

Figure 4. A model for measuring strategic barriers in standard estimation.

In Figure 5, the results of the confirmatory factor analysis are presented in the form of a standard estimation model. As is clear, all factor loads are at a reasonable level.

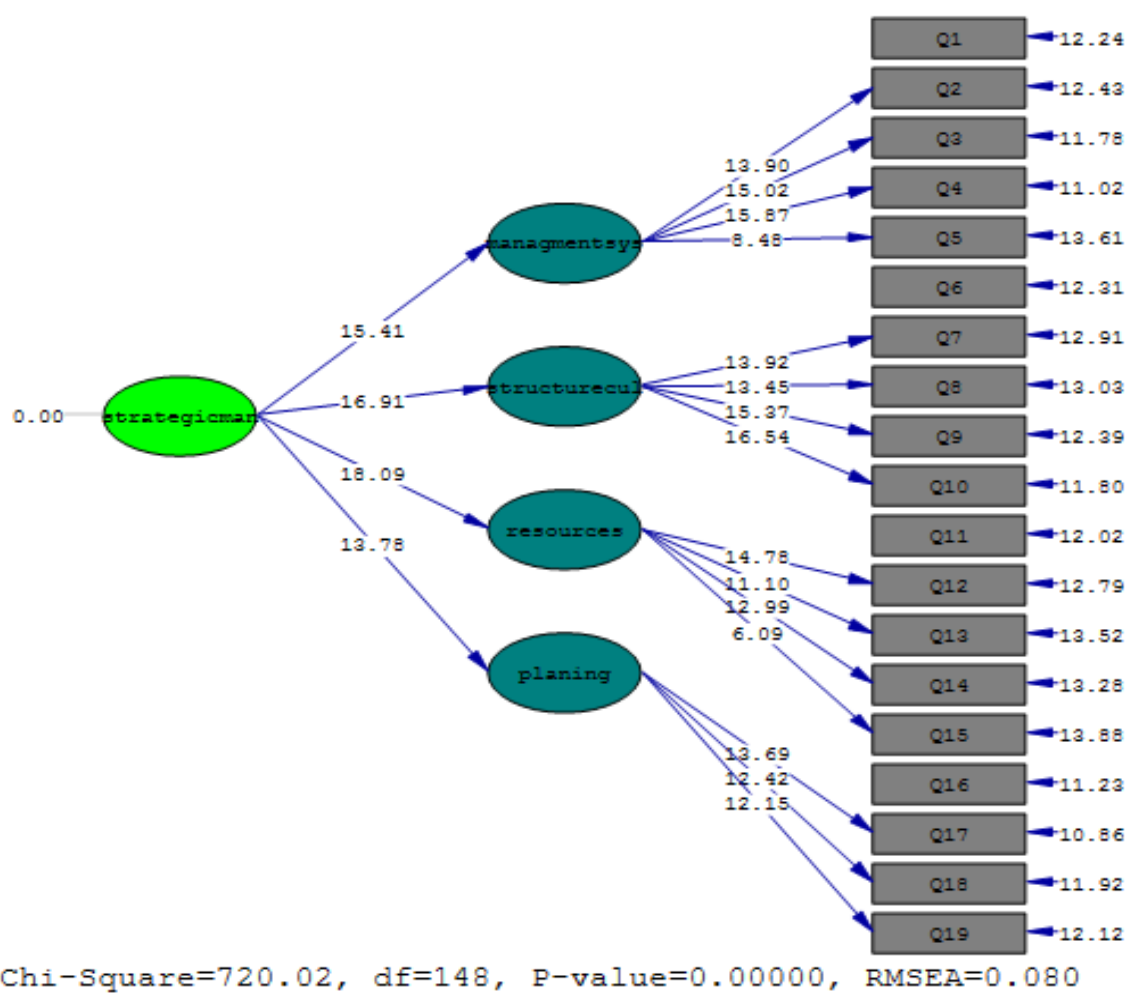

Figure 5. Correlation model. 
The fit indicators of the model indicate that the model is in a good status for fit and fit indicators. The results of the confirmatory factor analysis of the structural model are presented in Figure 5 in the form of the standard estimation model. All factor loads between dimensions and barriers are at a reasonable level and indicate the four dimensions of management and system barriers, barriers to non-allocation of resources, barriers related to employees, and barriers to strategic planning in the implementation of strategy in Tehran Telecommunication Center.

Since the ratio of $\chi 2$ to the degree of freedom $\left(\chi^{2} / \mathrm{DF}\right)$ is equal to 4.83 , which is close to the permitted value of 3 , and the mean square error (RMSEA) is equal to 0.08, which is lower that the acceptable value of 0.08 , all of these cases suggest that, given the results of the confirmatory factor analysis, one can rely on the structure of the strategic barriers and confirm the structure under discussion. Other fitting indices, including GFI, CFI, and NFI were 0.95, 0.91 and 0.90, respectively.

\section{7- Normality Test}

The results of statistical analysis are as follows.

$\mathrm{H}_{\mathrm{O}}$ : Distribution of data is normal.

$\mathrm{H}_{1}$ : Distribution of data is not normal.

According to the Kolmogorov-Smirnov test in Table 3, since the significance level is greater than 0.05, the nullhypothesis is confirmed and the with $0.95 \%$ level of confidence, it can be said that the distribution of the variables is normal and to carry out the research, parametric tests can be used. This is the most important condition for establishing the regression equation.

Table 3. Kolmogorov-Smirnov test.

\begin{tabular}{cc}
\hline Number & $\mathbf{9 0}$ \\
\hline Test statistics & 0.60 \\
\hline Level of significance & 0.86 \\
\hline & Normal \\
\hline
\end{tabular}

\section{8-Single Sample t-test}

It should be noted that, after examining the normal distribution of data by Kolmogorov test, one-sample t-test was used to measure 4 barrier components.

$\mathrm{H}_{0}: \mu<3 \quad$ the barriers of Tehran Telecommunication Center are below the average

$\mathrm{H}_{1}: \mu \geq 3$ the barriers of Tehran Telecommunication Center are not below the average

Table 4. One-sample t-test.

\begin{tabular}{llll}
\hline Factors & t-test & Sig. & Result \\
\hline System and management barrier & 5.27 & 0.000 & Confirmed \\
\hline Barriers related to non-allocation of resources & 4.36 & 0.000 & Confirmed \\
\hline Barriers related to employees & 4.56 & 0.000 & Confirmed \\
\hline Barriers to strategic planning & 6.22 & 0.000 & Confirmed \\
\hline
\end{tabular}

Given the items of the questionnaire, the mean obtained based on the Likert scale $(1,2,3,4$, and 5) is 3. According to Table 4 , since the significance level is less than 0.05 , H0 is rejected i.e. the barriers are in a satisfactory level. This means that there are almost no barriers in companies, and can only be addressed to improve it.

\section{9- TOPSIS Technique}

This model was proposed by Huang and Yun (1981). The basis of this technique is that the selected choice should have the minimum distance with the ideal positive solution (the best possible mode) and the greatest distance with the ideal negative solution. It is assumed that the desirability of each indicator is uniformly incremental or decreasing. The TOPSIS method consists of 7 steps. By creating a decision matrix including $\mathrm{m}$ options and $\mathrm{n}$ criteria. In this research, the $\mathrm{m}$ or the options studied are effective factors that are derived from the literature as well as the review of previous work and the questionnaire prepared by the experts. To measure the factors, five criteria (very small, low, moderate, high, and very large) were used for each of the numbers 1 to 5 to be seen in Table 5 . Due to the weighting of the options, and because of the positive and negative load that options can have in this method, the decision matrix is normalized before the start of the task. The numbers obtained from the distributed questionnaire make the decision matrix. In such a way that each person chooses a number or a certain criterion of the criteria mentioned in the previous section for each option or critical success factor. As a result, the number of people who selected that particular criterion will be placed 
in the cell corresponding to that table. The same procedure continues until all cells are taken in this way, then the matrix is normalized according to the above formula and is provided for the next step.

Table 5. The formation of the data matrix.

\begin{tabular}{cccccc}
\hline Factors & Too little & Little & Moderate & Much & $\begin{array}{c}\text { Very } \\
\text { much }\end{array}$ \\
\hline System and management barrier & 3 & 14 & 24 & 29 & 20 \\
\hline $\begin{array}{c}\text { Barriers related to non- } \\
\text { allocation of resources }\end{array}$ & 4 & 18 & 22 & 27 & 19 \\
\hline Barriers related to employees & 3 & 9 & 26 & 26 & 26 \\
\hline Barriers to strategic planning & 2 & 6 & 25 & 26 & 31 \\
\hline
\end{tabular}

Then the existing decision matrix is converted into a non-scale matrix using the relation whose results are shown in Table 6.

$N i j=\frac{x i j}{\sqrt{\sum_{i-1}^{m} x i j^{2}}}$

Table 6. Quantization and non-scalability of the decision matrix.

\begin{tabular}{cccccc}
\hline Factors & Too little & Little & Moderate & Much & Very much \\
\hline System and management barrier & 0.49 & 0.55 & 0.49 & 0.54 & 0.41 \\
\hline $\begin{array}{c}\text { Barriers related to non- } \\
\text { allocation of resources }\end{array}$ & 0.65 & 0.71 & 0.45 & 0.50 & 0.39 \\
\hline Barriers related to employees & 0.49 & 0.36 & 0.54 & 0.48 & 0.53 \\
\hline Barriers to strategic planning & 0.32 & 0.24 & 0.51 & 0.48 & 0.63 \\
\hline
\end{tabular}

Assigning weight to a normalized decision matrix is calculated as follows:

$\mathrm{Vij}=w \mathrm{wj} \times \mathrm{nij}$

In this study, an entropy method was used to calculate the weight matrix. The weight of each column is derived from the standard deviation of that column over the total deviation of that column. Then the resulting number is multiplied by the normalized matrix numbers and the weight matrix is obtained.

Table 7. Weighting using a normalized matrix.

\begin{tabular}{cccccc}
\hline Factors & Too little & Little & Moderate & Much & Very much \\
\hline Wi & 0.41 & 0.23 & 0.11 & 0.11 & 0.14 \\
\hline
\end{tabular}

As seen in Table 8, the weights obtained at this stage are multiplied by the normalized matrix to obtain the final matrix.

Table 8. Weighting the non-scale decision matrix.

\begin{tabular}{cccccc}
\hline Factors & Too little & Little & Moderate & Much & Very much \\
\hline System and management barrier & 0.20 & 0.13 & 0.05 & 0.06 & 0.06 \\
\hline $\begin{array}{c}\text { Barriers related to non- } \\
\text { allocation of resources }\end{array}$ & 0.27 & 0.16 & 0.05 & 0.05 & 0.05 \\
\hline Barriers related to employees & 0.20 & 0.08 & 0.06 & 0.05 & 0.07 \\
\hline Barriers to strategic planning & 0.13 & 0.05 & 0.06 & 0.05 & 0.09 \\
\hline
\end{tabular}

At this stage, the final matrix is ranked according to the following method. Identifying the ideal or non-ideal solution or alternative that is calculated as follows using the style Equation 3 and 4.

$A^{+}=\left\{(\max v i j \mid j \in J),\left(\min v i j \mid j \in J^{\prime}\right) \mid i=1,2, \ldots, m\right\}$

$A^{-}=\left\{(\min v i j \mid j \in J),\left(\max v i j \mid j \in J^{\prime}\right) \mid i=1,2, \ldots, m\right\}$

In this stage, ideal positive and negative alternatives are obtained, so that the furthest alternative to be the ideal negative solution and the closest alternative to the ideal positive solution can be found. For each column of the weight matrix, the ideal positive alternative (that is, the critical success factor which has achieved maximum score in this particular criterion) and the ideal negative alternative (that is, the critical success factor which has achieved minimum score in this particular criterion) have been calculated. Euclidean distance can be used to find the ideal positive and negative alternatives (Table 9). 
Table 9. Determining the ideal positive solution and the ideal negative solution.

\begin{tabular}{cccccc}
\hline & Too little & Little & Moderate & Much & Very much \\
\hline Max & 0.27 & 0.16 & 0.06 & 0.06 & 0.00 \\
\hline Min & 0.13 & 0.05 & 0.05 & 0.05 & 0.05 \\
\hline
\end{tabular}

Determining the distance of each alternative from the ideal solution is calculated as follows. This process is shown by Equation 5 .

$d_{i}^{+}=\sqrt{\sum_{j=1}^{n}\left(v_{j}^{+}-v_{i j}\right)^{2}}$

And the non-ideal solution is calculated as follow. This process is shown by Equation 6.

$d_{i}^{-}=\sqrt{\sum_{j=1}^{n}\left(v_{j}^{-}-v_{i j}\right)^{2}}$

Calculating relative proximity to the ideal alternative is shown in the formula below. This index represents the relative weight of the distance from which the alternative has an ideal negative. Therefore, the greater the $\mathrm{Ci}$ value for an alternative, the more the distance from the ideal negative is, and therefore the higher the rank than the other alternatives, and if we reduce that value by one, this index will indicate the distance from the ideal positive, so the higher its rank for the alternative, the higher rank it will have. This process is shown by Equation 7.

$c_{i}^{+}=d_{i}^{+} / d_{i}^{+}+d_{i}^{-}$

In the end, according to Table 10, the best alternative is an alternative that has a more relative proximity to the ideal solution and in fact has a higher $\mathrm{Ci}$. At this stage, the relative proximity to the ideal alternative has been calculated, and thus an alternative that has a relatively close proximity to the ideal solution is chosen as the best alternative.

Table 10. Prioritization of factors.

\begin{tabular}{lccc}
\hline \multicolumn{1}{c}{ ID } & +di & -di & CL \\
\hline System and management barrier & 0.08 & 0.01 & 0.55 \\
\hline Barriers related to non-allocation of resources & 0.14 & 0.11 & 0.44 \\
\hline Barriers related to employees & 0.11 & 0.08 & 0.41 \\
\hline Barriers to strategic planning & 0.11 & 0.14 & 0.56 \\
\hline
\end{tabular}

\section{Results}

A company or an organization needs to know where it will go and where exactly it is located, given its turbulent and dynamic business environment. After that, they must correctly formulate what they want and implement it.

Where is the main challenge in this regard? Previous research has suggested a major challenge in strategy implementation [7].

Implementation of a strategy is the stage of thought in operation. Although formulating a strategy is difficult, implementation of the strategy is even more difficult. The correct implementation of the strategy is a space that will help to defeat the success of the developed strategies and will make today the problem of implementing strategy becomes the most important challenge for managers in all organizations [8]. Implementing strategy in organizations has its own barriers and problems. Studying and recognizing the barriers to implementation and the failure factors of the strategic implementation plan and the presentation of the solutions to lower the factors will help its implementation to a great extent. Challenges will become opportunities if barriers are well-recognized and the necessary strategic environments are provided, and the benefits and merits of this valuable system will gradually become clear for everyone in an organization, from employees from the lowest to the highest, as well as to the managers of the organization. The main objective of this research was to identify barriers to the implementation of the strategic plan in Telecommunication Center in Tehran province.

In this research, it was strived to identify, categorize and rank the barriers to strategic implementation in Telecommunication Center of Tehran province, considering the importance and sensitivity of the implementation stage in the process of strategy management.

The results of this study were consistent with domestic and external studies such as Chukwumah \& Ezeugbor (2015), Therap et al. (2017) and Elbano (2016).

Experts believe that no development program in the organization will occur without providing the necessary background and context, and that examining the barriers to the implementation of strategies is one of these areas. The research findings in Tehran Telecommunication Center identified four barriers which, in order of priority, include: the barriers to strategic planning (0.56) ranked first, system and management barriers (0.55) ranked second, barriers to non- 
allocation of resources (0.44) in the third place, and barriers related to employees $(0.41)$ ranked fourth in the ranking. Each of these barriers has components that have been confirmed by their effective role in preventing the effective implementation of strategic plans of Telecommunication Center of Tehran province.

The results of the research showed that the most important and effective barrier components are strategic planning barriers. Its components include: "failure to create strategic culture, inappropriate linkage with strategy, transfer of operational strategy to operational level, lack of attention to planning, and inability to prioritize goals.

It seems strategic culture help us recognize strategic concepts and alignment with strategic objectives. Moreover, the effect of others' roles is also important. Strategic culture is an integral part of the organization, which suggests the deepening of operational activities in pursuit of the goals of the organization.

Developing a strategy in line with the vision and strategic objectives, it is important to orient the strategic planning and alignment of the programs and operations with the prioritized goals. By transferring the operational strategy at the operational level, the impact on the company's current programs is well represented.

The results of the ranking of barriers show that system and management barriers in the second place are preventing the implementation of the strategy in Tehran Telecommunication Center.

Among the most important components of this barrier are:

"Managers' lack of consciousness, managers' ambitions, and disapproval of others' views, internal disputes among senior executives, strategic review sessions by senior executives." According to the results of the research, timely consciousness of managers is important for creating a proper strategic plan and timely implementation of the strategies.

Ambitious administrators need to be aware of the changes leading to the strategy with justification and awareness. This reduces resilience in change and creates the necessary flexibility to accept the views of others.

Existence of sufficient training for managers in the institutionalization of this is very helpful. Reducing internal disputes and accepting large-scale strategies and changes at the organization or company level ensures the success of the strategy. Also, the existence of regular strategic review sessions can provide the necessary solutions to remove the leading barriers.

Then, non-allocation of resources was identified as the third barrier. The most important components in this regard are "identifying strategic businesses, lack of financial resources and equipment, weaknesses in the appropriate allocation of resources (financial and non-financial), weakness in resource budgeting and relationship with strategy, weakness in the allocation of knowledge and information".

Regarding the identification of strategic businesses, it is important to focus on strategic businesses to advance critical organizational strategies. Paying attention to the strategic development business plans is of special significance and separately budgeted. On the lack of financial resources and equipment for deployment of management systems, comprehensive systems of productivity and cost reduction can be pointed out. Paying attention to the proper allocation of resources (financial and non-financial) and examining the available capacities to align the levels of operations with the strategy will help to implement it. The weakness in resource budgeting and strategic relationship with strategic linkage to budgeting and budgeting through a balanced scorecard, if not well-executed, fails the organization.

It is true since budget is the backbone of planning. In order to better implement the strategies, financial discipline should be highlighted and enough effort should be made as well to allocate the necessary resources. Knowledge and information employs a range of activities that are used to manage, exchange, create, or promote intellectual capital at a macro level. Furthermore, intelligent design of processes, tools, structures, etc. with the intention of increasing, modernization with the help of knowledge and information is being developed. Covering the weakness of knowledge and information leads to reduce operating costs, accelerating the stages of product development, and improving customer service delivery and improving individual and organizational performance.

What is important in this regard are the knowledge sources, the technologies associated with them, processes and techniques, and most importantly, the human element that is the source of all knowledge. An organization or company that does not create the necessary motivation for knowledge sharing in its staff will lose a very large amount of its knowledge. The key point behind knowledge management is that improving all the factors leading to organizational success, such as organizational creativity, the quality of products and services, depends on the availability and efficient use of knowledge and information.

According to research findings, the barriers associated with employee discussions have earned the last rank in strategy implementation.

However, this does not mean that this barrier does not play a significant role in implementing the strategy and should not be taken into consideration, but less important than other barriers. According to the findings of the research, "the weakness in the training of employees for growth and learning, the failure of motivational factors in encouraging 
desirable behavior in the organization, weakness in human resource programs, weakness in employee participation and teamwork, lack of employee experience and expertise in strategy implementation" were identified as the most important barriers related to employees. Paying attention to growth and learning in individuals is one of the issues and areas that are needed to succeed in the strategy. If this is done with the help of the necessary training in the employees, common understanding of the members of the organization will be created by strategic culture. Training the employees and managers with the tools such as a balanced scorecard to help implement the strategy is very helpful. Also, with a focus on human resources, productivity increases and weaknesses decrease in this regard. Failure of motivational factors in encouraging desirable behavior in the organization, with the help of the employee awareness and incentive system, helps to achieve the goals. Human resources programs should always work to put into place programs such as employment, training, and job plans.

Employee participation increases the team spirit and cooperative spirit both within the organization and with the upstream institutions (especially knowledge based companies) in order to educate and promote the spirit of participatory culture. Moreover, the participation of key employees in the development of a strategy for creating a strategic microculture strategy will be created and the participation of members will reduce the negative attitudes in this regard. Organizations need to have highly experienced and experienced employees to increase productivity. In the changing environment of the organization, innovation and transformation is impossible without the employees' expertise and experience in implementing the strategy. Innovative companies need scientists and engineers who have enough experience and education in the basic technology of the organization.

Finally, it should be emphasized that by identifying the barriers to implementation of strategy in Telecommunications Center of Tehran province and identifying four barriers and its components, the managers and policymakers of the Tehran Telecommunication Center can use the model to implement the strategies with a view to removing the barriers. It should be noted that management is the strategy of an art, but what matters is the implementation of the strategy. Proper implementation of the strategies requires that the organization identifies annual goals and policies, motivates employees, and allocates resources and budgeting well so that the strategies are implemented. Implementing strategies requires strengthening the strategy, which means strengthening the structure and processes of the organization, strengthening the field of marketing and any value domain.

The implementation of the strategy must ultimately compensate for the employee's service and establish a reasonable relationship between performance and compensation for the employees since the implementation of the strategies is a practical stage of strategic development. The purpose of implementing strategies is to mobilize employees in the form of developed strategies.

A flawless implementation requires a seamless system that helps organizations to continuously improve the implementation of the strategy. Time and execution by senior executives and executive team members are used to maintain the coordination of processes for the successful implementation of the strategy.

It is suggested that Tehran Telecommunication Center and other government agencies of Tehran province analyze the environment prior to the development of the strategy and develop the strategies logically, taking into account the necessary fields of implementation of those programs far from any idealism. Creativity. When barriers gradually are recognized and sought to be removed, the effects of this will be clear from the lowest to the top rank for the organization's executives. It is also suggested to conduct a similar study in other government organizations in order to allow for the generalization of factors in state organizations. Also, a similar study in private organizations is proposed to expand the scope of studies and create scientific value added.

Finally, the managers and policymakers of the Telecommunication Center of Tehran province can use this model and instrument as a model to address all the barriers facing the implementation of the strategies.

\section{2- References}

[1] Elbanna, S., \& Fadol, Y. "An Analysis of the Comprehensive Implementation of Strategic Plans in Emerging Economies“. The United Arab Emirates as a Case Study. European Management Review (January, 2016).doi: 10.1111/emre.12068.

[2] Critenden, V., \& Critenden, W. "Building a capable organization: The eight levers of strategy implementation". Business Horizons, 51(4), 301-309. (July, august, 2008). doi: 10.1016/j.bushor.2008.02.003.

[3] Hwang C.L., Yoon K: "Multiple Attribute Decision Making: Methods and Applications“. Springer-Verlag, Berlin. . (1981). http://www.springer.com/gp/book/9783540105589.

[4] Jauch, L. R., \& Glueck, W. "Business policy and strategic management“, New York: McGraw-Hill, 1988.

[5] Li.Yang, Guohui. Sun, Eppler. Martin J. "Making strategy work: A literature review on the factors influencing strategy Implementation“, ICA Working Paper. 2. (2008) https://www.alexandria.unisg.ch/publications/54766.

[6] Zafar, F. Babar, S. Abbas, H. "The art of strategic management: a key to success in corporate sector", European Journal of Research and Reflection in Management Sciences. vol. 1 No. 1, (2013). www.idpublications.org. 
[7] Ines, Ghorbal-Blal. "The role of middle management in the execution of expansion strategies: The case of developers' selection of hotel projects“, International Journal of Hospitality Management. 30, 272-282. (2011). doi: 10.1016/j.ijhm.2010.09.007.

[8] Trapp, J. H., Kerber, H., \& Schramm, E. "Implementation and diffusion of innovative water infrastructures: obstacles, stakeholder networks and strategic opportunities for utilities“. Environmental Earth Sciences, 76(4), 154. (2017). doi: 10.1007/s12665-017-6461-8. 